\title{
Deposition of osmium thin films using pyrazolate complexes as CVD source reagents
}

\author{
Yun Chi, ${ }^{* a}$ Huan-Li Yu, ${ }^{a}$ Wei-Li Ching, ${ }^{a}$ Chao-Shiuan Liu, ${ }^{a}{ }^{a}$ Yao-Lun Chen, ${ }^{a}$ \\ Tsung-Yi Chou, ${ }^{a}$ Shie-Ming Peng ${ }^{b}$ and Gene-Hsiang Lee ${ }^{b}$ \\ ${ }^{a}$ Department of Chemistry, National Tsing Hua University, Hsinchu 30013 Taiwan, Republic \\ of China. Fax: (886) 3 572-0864; E-mail: ychi@mx.nthu.edu.tw \\ ${ }^{b}$ Department of Chemistry and Instrumentation Center, National Taiwan University, Taipei \\ 10764 Taiwan, Republic of China
}

\author{
Received 9th October 2001, Accepted 12th February 2002 \\ First published as an Advance Article on the web 22nd March 2002
}

\begin{abstract}
The reaction of $\mathrm{Os}_{3}(\mathrm{CO})_{12}$ with 1.2 eq. of pyrazole $\left(3,5-\left(\mathrm{CF}_{3}\right)_{2}-\mathrm{pz}\right) \mathrm{H}$ at $190{ }^{\circ} \mathrm{C}$ affords triosmium complex $\mathrm{Os}_{3}(\mathrm{CO})_{10}\left(3,5-\left(\mathrm{CF}_{3}\right)_{2}-\mathrm{pz}\right)(\mu-\mathrm{H})(\mathbf{1})$ as the isolable product. Upon further treatment with excess pyrazole $\left(3,5-\left(\mathrm{CF}_{3}\right)_{2}-\mathrm{pz}\right) \mathrm{H}$ under more forcing conditions, complex 1 converts to a diosmium pyrazolate complex $\left[\mathrm{Os}(\mathrm{CO})_{3}\left(3,5-\left(\mathrm{CF}_{3}\right)_{2}-\mathrm{pz}\right)\right]_{2}(2)$ in high yield. These osmium complexes are characterized by spectroscopic methods and single crystal X-ray diffraction study, showing the expected triangular and linear Os-Os backbone and with one and two bridging pyrazolate ligands for complexes $\mathbf{1}$ and $\mathbf{2}$, respectively. The thermal properties are studied by TG analysis and the deposition experiments are carried out using a cold-wall CVD apparatus. The as-deposited thin films are characterized using XPS, XRD and SEM and electrical resistivity measurement. It seems that the Os metal thin films are best deposited at an optimal temperature of $450-500{ }^{\circ} \mathrm{C}$ and using complex 2 as the source reagent.
\end{abstract}

The deposition of transition-metal thin films by chemical vapor deposition (CVD), in contrast to the use of physical vapor deposition and sputtering techniques, offers better uniform coverage, faster growth rate and greater substrate selectivity in microelectronic applications. ${ }^{1}$ As a result, many studies have been employed to deposit transition metal-containing thin films, ${ }^{2}$ and Os metal is no exception as it may find applications such as in fabrication of methane-detection chemical sensors, $\mathrm{X}$-ray mask materials and thermionic diodes, and for making electrical contacts and conductive coating with good secondary electron emission efficiency. ${ }^{3}$

Osmium metal is highly refractory with melting point 3033 $\pm 30^{\circ} \mathrm{C}$, thus CVD should be more suitable for deposition of Os metal as direct evaporation may require excessively high temperatures, while physical sputtering may introduce defects on the substrate surface by energetic ion and electron bombardment. Since the first successful deposition of Os metal by hydrogen reduction of $\mathrm{OsCl}_{4}$ vapor, ${ }^{4}$ only a few reports have been focused on its continued improvement. In recent years, work on the chemical vapor deposition of osmium has started to utilize the commercially available osmocene $\left(\mathrm{C}_{5} \mathrm{H}_{5}\right)_{2} \mathrm{Os},{ }^{5}$ osmium tetraoxide $\mathrm{OsO}_{4},{ }^{6}$ or even the metal carbonyl complexes such as $\mathrm{Os}(\mathrm{CO})_{5},{ }^{7} \mathrm{Os}_{3}(\mathrm{CO})_{12},{ }^{8}$ and $\mathrm{Os}(\mathrm{CO})_{4}(\mathrm{hfb}),{ }^{9,10}$ where $\mathrm{hfb}=$ hexafluorobut-2-yne, to produce pure osmium metal or the respective metal oxide material $\mathrm{OsO}_{2}$. It has been reported that thin films with reasonable purity were obtained in most of the previous studies; however, the usage of these source reagents has encountered difficulties such as the greater toxicity of $\mathrm{OsO}_{4}$, poor thermal stability of $\mathrm{Os}(\mathrm{CO})_{5}$, and lower gas phase transportation capability for the osmocene complex $\left(\mathrm{C}_{5} \mathrm{H}_{5}\right)_{2} \mathrm{Os}$ and polynuclear metal complex $\mathrm{Os}_{3}(\mathrm{CO})_{12}$.

Recently, a mononuclear osmium complex $f a c-O s(C O)_{3^{-}}$ (hfac)(tfa), where $\mathrm{tfa}=$ trifluoroacetate and hfac $=$ hexafluoroacetylacetonate, was synthesized from the direct reaction of the parent carbonyl compound $\mathrm{Os}_{3}(\mathrm{CO})_{12}$ and fluorinated $\beta$-diketonate ligand (hfac)H. ${ }^{11}$ Unlike other literature precedents, these monometallic complexes exhibit excellent volatility and can be readily converted to metallic osmium at the deposition temperature of $400-500{ }^{\circ} \mathrm{C}$, showing all the necessary characteristics required for CVD experiments. In order to further extend this research endeavor, we have synthesized two more carbonyl complexes containing other types of fluorinated ligand, namely the pyrazolate metal complexes $\mathrm{Os}_{3}(\mathrm{CO})_{10}\left(3,5-\left(\mathrm{CF}_{3}\right)_{2}-\mathrm{pz}\right)(\mu-\mathrm{H})(\mathbf{1})$ and $\left[\mathrm{Os}(\mathrm{CO})_{3^{-}}\right.$ $\left.\left(3,5-\left(\mathrm{CF}_{3}\right)_{2}-\mathrm{pz}\right)\right]_{2}$ (2). This new class of metal carbonyl is expected to exhibit an enhanced volatility with respect to their parent compound $\mathrm{Os}_{3}(\mathrm{CO})_{12}$, and thus should be equally suitable for depositing osmium thin films.

\section{Experimental}

\section{General information and materials}

Mass spectra were obtained on a JEOL SX-102A instrument operating in electron impact (EI) mode, and infrared spectra were recorded on a Perkin-Elmer 2000 FT-IR spectrometer. The ${ }^{1} \mathrm{H},{ }^{13} \mathrm{C}$ and ${ }^{19} \mathrm{~F}$ NMR spectra were recorded on Varian Mercury-400 or Inova-500 instruments; chemical shifts are quoted with respect to internal standard tetramethylsilane for ${ }^{1} \mathrm{H}$ and ${ }^{13} \mathrm{C} \mathrm{NMR}$ data and $\mathrm{CFCl}_{3}$ for ${ }^{19} \mathrm{~F}$ NMR data. The thermogravimetric analyses (TGA) were recorded on a Seiko TG/DTA 300 instrument under $\mathrm{N}_{2}$ at $1 \mathrm{~atm}$, with a constant flow rate of $100 \mathrm{sccm}$ and a heating rate of $10{ }^{\circ} \mathrm{C} \mathrm{min}{ }^{-1}$. Elemental analyses were carried out at the NSC Regional Instrumentation Center at National Cheng Kung University, Tainan, Taiwan. The pyrazole ligand $\left(3,5-\left(\mathrm{CF}_{3}\right)_{2}-\mathrm{pz}\right) \mathrm{H}$ was prepared according to the method reported in the literature. ${ }^{12}$ All reactions were performed in air using anhydrous solvents or solvents treated with appropriate drying reagent.

The identification of osmium thin films was carried out using an X-ray diffractometer (XRD) with $\mathrm{Cu} \mathrm{K} \alpha$ radiation. Scanning electron microscopy (SEM) was recorded on a Hitachi S-4000 system. The electrical resistivity of films was 
Table 1 Crystal data and structure refinement parameters for complexes $\mathbf{1}$ and $2 \dagger$

\begin{tabular}{|c|c|c|}
\hline Complex & 1 & 2 \\
\hline Empirical formula & $\mathrm{C}_{15} \mathrm{HF}_{6} \mathrm{~N}_{2} \mathrm{O}_{10} \mathrm{Os}_{3}$ & $\mathrm{C}_{16} \mathrm{H}_{2} \mathrm{~F}_{12} \mathrm{~N}_{4} \mathrm{O}_{6} \mathrm{Os}_{2}$ \\
\hline Formula weight & 1053.78 & 954.62 \\
\hline Crystal system & Monoclinic & Tetragonal \\
\hline Space group & $P 2(1) / c$ & $P \overline{4} 2(1) m$ \\
\hline$a / \AA$ & $16.7057(4)$ & $11.9181(2)$ \\
\hline$b / \AA$ & $7.7137(2)$ & $11.9181(2)$ \\
\hline$\beta /^{\circ}$ & $114.524(1)$ & \\
\hline Volume $/ \AA^{3}$ & $2207.87(10)$ & $1164.86(4)$ \\
\hline$Z$ & 4 & 2 \\
\hline Density (calculated) $/ \mathrm{Mg} \mathrm{m}^{-3}$ & 3.173 & 2.722 \\
\hline Absorption coefficient $/ \mathrm{mm}^{-1}$ & 17.328 & 11.036 \\
\hline$F(000)$ & 1872 & 868 \\
\hline Crystal size $/ \mathrm{mm}^{3}$ & $0.30 \times 0.25 \times 0.20$ & $0.39 \times 0.30 \times 0.30$ \\
\hline$\theta$ ranges & 1.34 to $27.50^{\circ}$ & 2.42 to $27.50^{\circ}$ \\
\hline Reflections collected & 18414 & 12364 \\
\hline Independent reflections & $5057[R($ int $)=0.0465]$ & $1437[R($ int $)=0.0426]$ \\
\hline Data/restraints/parameters & $5057 / 0 / 330$ & $1437 / 0 / 98$ \\
\hline Goodness-of-fit on $F^{2}$ & 1.086 & 1.094 \\
\hline Final $R$ indices $[I>2 \sigma(I)]$ & $R_{1}=0.0297, w R_{2}=0.0790$ & $R_{1}=0.0146, w R_{2}=0.0363$ \\
\hline$R$ indices (all data) & $R_{1}=0.0385, w R_{2}=0.0882$ & $R_{1}=0.0157, w R_{2}=0.0365$ \\
\hline Largest diff. peak and hole/e $\AA^{-3}$ & 1.908 and -1.856 & 0.625 and -0.680 \\
\hline
\end{tabular}

measured by a four-point probe method at room temperature, for which the instrument is assembled using a Keithley 2182 nanovoltmeter and a Keithley 2400 constant current source. The elemental composition was determined by X-ray photoelectron spectroscopy (XPS) utilizing a Physical Electronics PHI 1600 system with an $\mathrm{Al} / \mathrm{Mg}$ dual anode X-ray source, and the XPS spectra were collected after 1-2 min sputtering with argon at $4 \mathrm{keV}$ until a constant composition was obtained.

\section{Synthesis of complex 1}

A $160 \mathrm{~mL}$ stainless steel autoclave was charged with $0.14 \mathrm{~g}$ of $\left(3,5-\left(\mathrm{CF}_{3}\right)_{2}-\mathrm{pz}\right) \mathrm{H}(0.68 \mathrm{mmol}), 0.5 \mathrm{~g}$ of $\mathrm{Os}_{3}(\mathrm{CO})_{12}(0.55 \mathrm{mmol})$ and $50 \mathrm{~mL}$ of anhydrous hexane. The autoclave was sealed and the mixture was heated to $190{ }^{\circ} \mathrm{C}$ for 18 hours. After opening the autoclave, the hexane solvent was removed and the solid residue was then purified by recrystallization in warm $\mathrm{CH}_{2} \mathrm{Cl}_{2}$ solution, giving $0.54 \mathrm{~g}$ of a yellow crystalline sample $\mathrm{Os}_{3}(\mathrm{CO})_{10}\left(3,5-\left(\mathrm{CF}_{3}\right)_{2}-\mathrm{pz}\right)(\mu-\mathrm{H}) \quad(1,0.51 \mathrm{mmol}, 92 \%)$ which melted at $174-175{ }^{\circ} \mathrm{C}$.

Spectral data of 1: MS (FAB, $\left.{ }^{192} \mathrm{Os}\right), \mathrm{m} / \mathrm{z} 1059, \mathrm{M}^{+}$. IR $\left(\mathrm{C}_{6} \mathrm{H}_{12}\right): v(\mathrm{CO}), 2116(\mathrm{~m}), 2079$ (vs), 2067 (vs), 2033 (vs), 2021 (vs), 2016 (s), 1997 (vw), 1991(m) $\mathrm{cm}^{-1}$. ${ }^{1} \mathrm{H}$ NMR (400 MHz, $\left.\mathrm{CDCl}_{3}, 294 \mathrm{~K}\right): \delta 6.59$ (s, CH), -12.61 (s, Os-H-Os). ${ }^{13} \mathrm{C} \mathrm{NMR}$ (125 MHz, $\left.\mathrm{CDCl}_{3}, 298 \mathrm{~K}\right): \delta 180.9$ (s, CO), 180.6 (s, CO), 175.6 (s, 2CO), 173.5 (s, 2CO), 172.8 (s, 2CO), $171.5(\mathrm{~s}, 2 \mathrm{CO}), 143.8$ $\left(\mathrm{q},{ }^{2} J_{\mathrm{CF}}=39 \mathrm{~Hz}, 2 C\left(\mathrm{CF}_{3}\right)\right), 120.6\left(\mathrm{q},{ }^{1} J_{\mathrm{CF}}=270 \mathrm{~Hz}, 2 \mathrm{CF}_{3}\right)$, 109.6 (s, CH). ${ }^{19} \mathrm{~F}$ NMR $\left(470 \mathrm{MHz}, \mathrm{CDCl}_{3}, 298 \mathrm{~K}\right): \delta-60.1$ (6F). Anal. Calcd. for $\mathrm{C}_{15} \mathrm{H}_{2} \mathrm{~F}_{6} \mathrm{~N}_{2} \mathrm{O}_{10} \mathrm{Os}_{3}: \mathrm{C}, 17.08 ; \mathrm{N}, 2.66 ; \mathrm{H}$, 0.19 . Found: C, $17.10 ; \mathrm{N}, 2.77 ; \mathrm{H}, 0.28 \%$.

\section{Synthesis of complex 2}

A $160 \mathrm{~mL}$ stainless steel autoclave was charged with $0.60 \mathrm{~g}$ of $\left(3,5-\left(\mathrm{CF}_{3}\right)_{2}-\mathrm{pz}\right) \mathrm{H}(2.94 \mathrm{mmol}), 0.5 \mathrm{~g}$ of $\mathrm{Os}_{3}(\mathrm{CO})_{10}\left(3,5-\left(\mathrm{CF}_{3}\right)_{2}-\right.$ $\mathrm{pz})(\mu-\mathrm{H})(1,0.47 \mathrm{mmol})$ and $40 \mathrm{~mL}$ of anhydrous hexane. The autoclave was sealed and the mixture heated to $190{ }^{\circ} \mathrm{C}$ for 40 hours. After the reaction was completed, the hexane solvent was removed under vacuum, and the solid residue purified by recrystallization from a warm $\mathrm{CH}_{2} \mathrm{Cl}_{2}$ solution, giving $0.58 \mathrm{~g}$ of a colorless product $\left[\mathrm{Os}(\mathrm{CO})_{3}\left(3,5-\left(\mathrm{CF}_{3}\right)_{2}-\mathrm{pz}\right)\right]_{2}(2,0.61 \mathrm{mmol}$, $86 \%$ ) which melted at $189-190{ }^{\circ} \mathrm{C}$.

$\dagger$ CCDC reference numbers 172179 and 172180. See http://www.rsc.org/ suppdata/jm/b1/b109150f/ for crystallographic files in .cif format.
Spectral data of 2: MS (FAB, $\left.{ }^{192} \mathrm{Os}\right), \mathrm{m} / \mathrm{z}$ 958, $\mathrm{M}^{+}$. IR $\left(\mathrm{C}_{6} \mathrm{H}_{12}\right): v(\mathrm{CO}), 2108$ (m), 2078 (vs), 2033 (s), 2024 (vs) $\mathrm{cm}^{-1}$. ${ }^{1} \mathrm{H}$ NMR $\left(400 \mathrm{MHz}, \mathrm{CDCl}_{3}, 294 \mathrm{~K}\right): \delta 6.76(\mathrm{~s}, \mathrm{CH}) .{ }^{13} \mathrm{C} \mathrm{NMR}$ $\left(125 \mathrm{MHz}, \mathrm{CDCl}_{3}, 298 \mathrm{~K}\right): \delta 178.3$ (s, 4CO), 169.3 (s, 2CO), $143.6\left(\mathrm{q},{ }^{2} J_{\mathrm{CF}}=40 \mathrm{~Hz}, 2 C\left(\mathrm{CF}_{3}\right)\right), 120.4\left(\mathrm{q},{ }^{1} J_{\mathrm{CF}}=270 \mathrm{~Hz}\right.$, $\left.2 \mathrm{CF}_{3}\right), 107.3(\mathrm{~s}, \mathrm{CH}) .{ }^{19} \mathrm{~F} \mathrm{NMR}\left(470 \mathrm{MHz}, \mathrm{CDCl}_{3}, 298 \mathrm{~K}\right): \delta$ -60.0 (12F). Anal. Calcd. for $\mathrm{C}_{16} \mathrm{H}_{2} \mathrm{~F}_{12} \mathrm{~N}_{4} \mathrm{O}_{6} \mathrm{Os}_{2}$ : C, 20.13; N, 5.87; H, 0.21. Found: C, 19.90; N, 5.99; H, 0.30\%.

\section{X-Ray Crystallography}

Single crystal X-ray diffraction studies were carried out on a Bruker SMART CCD diffractometer using $\lambda(\mathrm{Mo}-\mathrm{K} \alpha)$ radiation $0.7107 \AA$ at room temperature. All the crystallographic data were collected over a hemisphere of reciprocal space by a combination of three sets of exposures. Each set had a different $\varphi$ angle for the crystal and each exposure of 10 seconds covered $0.30^{\circ}$ in $\omega$. The data collection was executed using the SMART program. An empirical absorption was based on the symmetryequivalent reflections and applied to the data using the SADABS program. The structures were solved using the SHELXTL-97 program. ${ }^{13}$ The crystallographic refinement parameters of complexes $\mathbf{1}$ and $\mathbf{2}$ are summarized in Table 1, while their selected bond distances and angles are given in Tables 2 and 3, respectively.

\section{CVD Procedures}

The thermal CVD reactions were carried using a vertical coldwall reactor; its schematic setup is depicted in Fig. 1.

The CVD chamber consists of a Pyrex glass cylinder $20 \mathrm{~cm}$ in length and $9 \mathrm{~cm}$ in diameter mounted on a stainless steel stand.

Table 2 Selected bond lengths [Å] for complex 1

\begin{tabular}{llll}
\hline Os(1)-Os(2) & $2.9135(4)$ & Os(1)-Os(3) & $2.8685(4)$ \\
Os(2)-Os(3) & $2.8642(4)$ & Os(1)-N(1) & $2.153(6)$ \\
Os(2)-N(2) & $2.141(6)$ & Os(1)-C(1) & $1.888(8)$ \\
Os(1)-C(2) & $1.899(8)$ & Os(1)-C(3) & $1.932(8)$ \\
Os(2)-C(4) & $1.943(9)$ & Os(2)-C(5) & $1.932(8)$ \\
Os(2)-C(6) & $1.899(8)$ & Os(3)-C(7) & $1.949(8)$ \\
Os(3)-C(8) & $1.942(8)$ & Os(3)-C(9) & $1.926(8)$ \\
Os(3)-C(10) & $1.924(9)$ & $\mathrm{N}(1)-\mathrm{N}(2)$ & $1.360(8)$ \\
$\mathrm{N}(1)-\mathrm{C}(12)$ & $1.332(10)$ & $\mathrm{N}(2)-\mathrm{C}(14)$ & $1.334(9)$ \\
$\mathrm{C}(12)-\mathrm{C}(13)$ & $1.366(11)$ & $\mathrm{C}(13)-\mathrm{C}(14)$ & $1.377(11)$ \\
Os(1)-H(1) & $1.79(6)$ & $\mathrm{Os}(2)-\mathrm{H}(1)$ & $1.80(6)$ \\
\hline
\end{tabular}


Table 3 Selected bond lengths [Å] for complex 2

\begin{tabular}{llll}
\hline Os(1)-Os(1A) & $2.7457(4)$ & Os(1)-N(1) & $2.126(3)$ \\
Os(1)-C(1) & $1.904(5)$ & Os(1)-C(2) & $1.960(6)$ \\
$\mathrm{C}(1)-\mathrm{O}(1)$ & $1.133(6)$ & $\mathrm{C}(2)-\mathrm{O}(2)$ & $1.136(8)$ \\
$\mathrm{N}(1)-\mathrm{N}(1 \mathrm{~B})$ & $1.334(6)$ & $\mathrm{N}(1)-\mathrm{C}(4)$ & $1.347(5)$ \\
$\mathrm{C}(3)-\mathrm{C}(4)$ & $1.382(6)$ & & \\
\hline
\end{tabular}

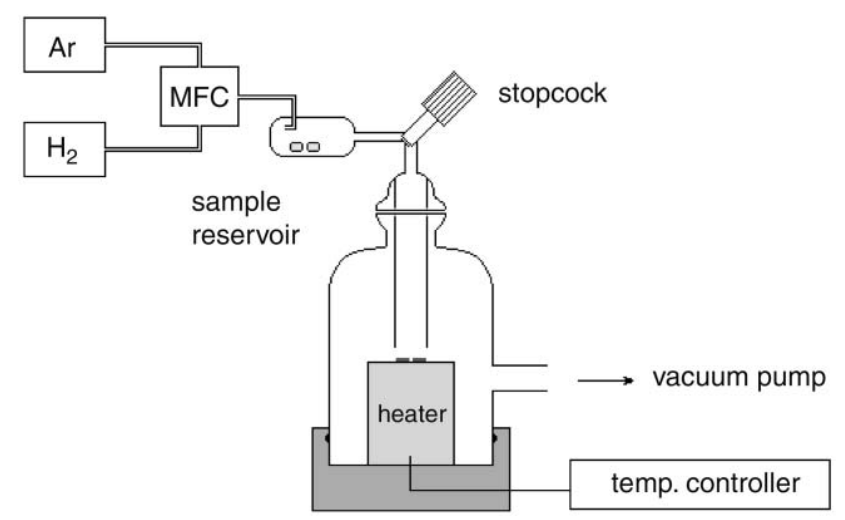

Fig. 1 Schematic diagram of the CVD apparatus.

The sample reservoir and pipeline leading to the CVD chamber were heated to $110{ }^{\circ} \mathrm{C}$ for triosmium complex 1 and $115^{\circ} \mathrm{C}$ for diosmium complex $\mathbf{2}$ by a heating tape. Carrier gas was introduced through the sidearm of the sample reservoir, which was loaded 50-75 $\mathrm{mg}$ of the source reagent during each CVD experiment. After mixing with vapor of the source reagent, the carrier gas then passed into the CVD chamber, and contacted with $\mathrm{Si}$ wafers placed at the center of the substrate heater where deposition occurred. The flow rate of carrier gas was adjusted to $10-20 \mathrm{sccm}$. The deposition time was typically adjusted to $10 \mathrm{~min}$ to $15 \mathrm{~min}$. Before each experiment, the Si wafers were cleaned using dilute HF solution, followed by deionized water and acetone in sequence, and dried under nitrogen.

\section{Results and discussion}

\section{Synthesis and characterization}

The osmium carbonyl complex $\mathrm{Os}_{3}(\mathrm{CO})_{12}$ reacted with 1.25 eq. of pyrazole $\left(3,5-\left(\mathrm{CF}_{3}\right)_{2}-\mathrm{pz}\right) \mathrm{H}$ in a hexane solution at $190{ }^{\circ} \mathrm{C}$ to give a yellow cluster product $\mathrm{Os}_{3}(\mathrm{CO})_{10}\left(3,5-\left(\mathrm{CF}_{3}\right)_{2}-\mathrm{pz}\right)(\mu-\mathrm{H})$ (1). This product was purified by recrystallization from a mixture of $\mathrm{CH}_{2} \mathrm{Cl}_{2}$ and hexane. The FAB mass analysis showed a molecular ion at $\mathrm{m} / \mathrm{z} 1059$, corresponding to a molecular formula $\mathrm{C}_{15} \mathrm{H}_{2} \mathrm{~F}_{6} \mathrm{~N}_{2} \mathrm{O}_{10} \mathrm{Os}_{3}$. The observation of this ion suggests that the pyrazolate ligand has coordinated to the triosmium framework with concurrent elimination of two CO ligands. In good agreement with this observation, the ${ }^{1} \mathrm{H}$ NMR spectrum of $\mathbf{1}$ exhibited a methyne signal of the pyrazolate ligand at $\delta 6.59$ and a high-field resonance signal at $\delta-12.61$, which indicates the formation of an Os- $\mathrm{H}-\mathrm{Os}$ hydride ligand. The IR $v(\mathrm{CO})$ pattern was very similar to that of the structurally characterized imidazole complex $\mathrm{Os}_{3}(\mathrm{CO})_{10}\left(\mu-\mathrm{N}_{2} \mathrm{C}_{3} \mathrm{H}_{3}\right)(\mu-\mathrm{H}),{ }^{14}$ which thus gave confirmation of the structure.

Moreover, further treatment of the pyrazolate complex $\mathbf{1}$ with pyrazole ligand under more forcing conditions has afforded a colorless dimer compound $\mathrm{Os}(\mathrm{CO})_{3}\left(3,5-\left(\mathrm{CF}_{3}\right)_{2}-\right.$ $\mathrm{pz}]_{2}$ (2) in $86 \%$ yield. The identification was achieved using FAB mass analysis, IR and NMR spectroscopy. Of particular importance was the ${ }^{1} \mathrm{H}$ NMR spectrum, for which one signal at $\delta 6.76$ was observed due to the pyrazolate ligand, but which showed no high-field resonance signal due to the bridging hydride ligand. Hence, it seems that the addition of the second pyrazolate ligand has induced a facile elimination of hydride in $\mathbf{1}$, followed by degradation of the triosmium framework, giving the diosmium complex 2 with two bridging pyrazolate ligands. The sequential transformation can be depicted according to eqn. 1 and 2 listed below:

$$
\begin{gathered}
\mathrm{Os}_{3}(\mathrm{CO})_{12}+\left(3,5-\left(\mathrm{CF}_{3}\right)_{2}-\mathrm{pz}\right) \mathrm{H} \rightarrow \\
\mathrm{Os}_{3}(\mathrm{CO})_{10}\left(3,5-\left(\mathrm{CF}_{3}\right)_{2}-\mathrm{pz}\right)(\mu-\mathrm{H})(\mathbf{1})+2 \mathrm{CO} \\
(\mathbf{1})+2\left(3,5-\left(\mathrm{CF}_{3}\right)_{2}-\mathrm{pz}\right) \mathrm{H} \rightarrow \\
3 / 2\left[\mathrm{Os}(\mathrm{CO})_{3}\left(3,5-\left(\mathrm{CF}_{3}\right)_{2}-\mathrm{pz}\right)\right]_{2}(\mathbf{2})+3 / 2 \mathrm{H}_{2}+\mathrm{CO}
\end{gathered}
$$

X-Ray diffraction studies were carried out to establish their molecular structures. As indicated in Fig. 2, the complex 1 consists of three Os atoms that form an isosceles triangle with distances Os(1)-Os(2) $=2.9135(4), \operatorname{Os}(1)-\mathrm{Os}(3)=2.8685(4)$ and Os(2)-Os(3) = 2.8642(4) $\AA$, of which the longer Os-Os edge is bridged by the pyrazolate ligand and a hydride ligand at the opposite position, with distances Os(1)-H(1) = 1.79(6) and $\mathrm{Os}(2)-\mathrm{H}(1)=1.80(6) \AA$. Basically, this structure can be considered to derive from the parent complex $\mathrm{Os}_{3}(\mathrm{CO})_{12}$ by replacement of two axial $\mathrm{CO}$ groups on adjacent Os atoms by the bridging pyrazolate and hydride ligands. An analogous molecular structure was documented for the ruthenium analogue $\mathrm{Ru}_{3}(\mathrm{CO})_{10}\left(3,5-\left(\mathrm{CF}_{3}\right)_{2}-\mathrm{pz}\right)(\mu-\mathrm{H}){ }^{15}$

The ORTEP diagram of the dimer complex $\mathbf{2}$ is shown in Fig. 3. It is notable that the molecule has crystallographic $\mathrm{mm}$ symmetry and consequently the asymmetric unit contains a one-quarter molecule. For each individual complex molecule, two Os atoms, separated by the distance 2.7434(5) $\AA$, are doubly bridged by two pyrazolate ligands coordinated through their nitrogen atoms. Each osmium atom is in an octahedral environment, being bonded to three terminal $\mathrm{CO}$ ligands, the second Os atom, and two nitrogen atoms from pyrazolate ligands, which are nearly orthogonal to each other. The axial Os-CO distance $(\mathrm{Os}(1)-\mathrm{C}(2)=1.960(6) \AA)$ is slightly longer than those found for the equatorial $\mathrm{CO}$ ligands $\mathrm{Os}(1)-\mathrm{C}(1)=$ 1.904(5) $\AA$. This lengthening of axial Os-C bonds has been observed in the related osmium diketonate complex $\left[\mathrm{Os}(\mathrm{CO})_{3}(\mathrm{thd})\right]_{2}$, where thd $=$ 2,2,6,6-tetramethylheptane3,5 -dionate, ${ }^{16}$ and the ruthenium pyrazolate complex $\left[\mathrm{Ru}(\mathrm{CO})_{3}\left(3,5-\mathrm{Me}_{2}-\mathrm{pz}\right)\right]_{2},{ }^{17}$ showing a labilization effect produced by the trans-directing metal-metal linkage.

Concerning the properties relevant to CVD experiments, both complexes $\mathbf{1}$ and $\mathbf{2}$ can be readily sublimed below $100{ }^{\circ} \mathrm{C}$ under vacuum (320 mTorr), showing a good pattern of

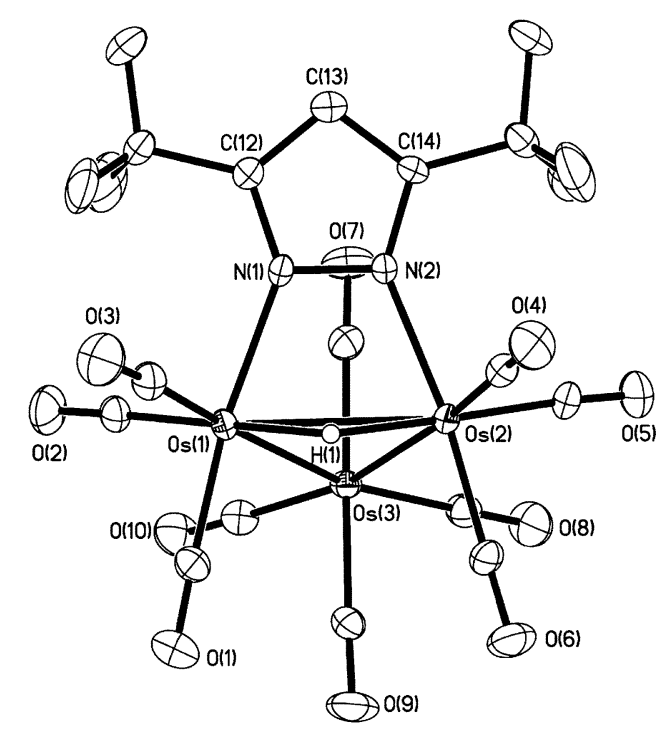

Fig. 2 ORTEP drawing of complex 1 with thermal ellipsoids shown at the $30 \%$ probability level. 


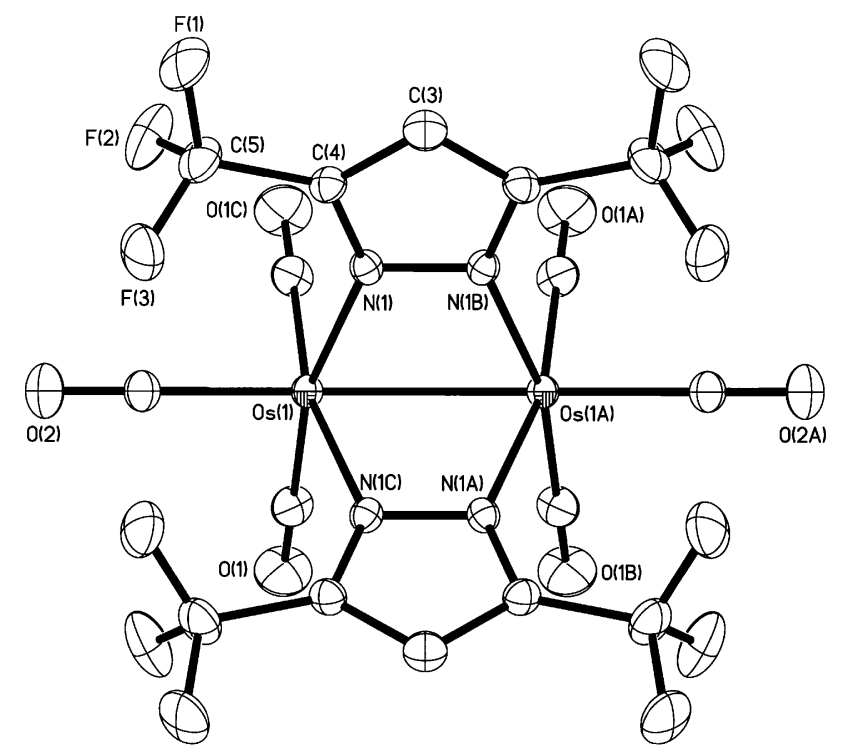

Fig. 3 ORTEP drawing of complex 2 with thermal ellipsoids shown at the $30 \%$ probability level.

volatility vs. thermal stability. Thermogravimetric analysis carried out at atmospheric pressure with $\mathrm{N}_{2}$ as the carrier gas exhibits a slow decrease of weight at the temperature of 130 $160{ }^{\circ} \mathrm{C}$, with the onset temperature of complex 2 being slightly lower (Fig. 4). It is notable that the complex 1 gives a rapid loss of weight centered at about $220{ }^{\circ} \mathrm{C}$ due to direct evaporation and affords a residual weight of $0.1 \%$ at $500{ }^{\circ} \mathrm{C}$. On the other hand, complex 2 shows a sudden loss of weight at a temperature $30{ }^{\circ} \mathrm{C}$ lower, while no metallic residue is obtained upon increasing the temperature to $500{ }^{\circ} \mathrm{C}$. The enhanced volatility of $\mathbf{2}$ may be due to the attachment of four $\mathrm{CF}_{3}$ groups vs. two $\mathrm{CF}_{3}$ substituents of $\mathbf{1}$, for which the repulsive force between lone pairs of fluorine atoms and the low polarizability of the $\mathrm{C}-\mathrm{F}$ bonds are two most important contributing factors. ${ }^{18}$

In addition, the $\mathrm{TG}$ analysis of the parent complex $\mathrm{Os}_{3}(\mathrm{CO})_{12}$ is also recorded for purposes of comparison. A two-stage loss of weight was clearly observed, the first one occurring at $160-250{ }^{\circ} \mathrm{C}$ and the second starting at temperatures exceeding $250{ }^{\circ} \mathrm{C}$, presumably due to a combination of sample evaporation and $\mathrm{CO}$ dissociation. The later could probably give the formation of less volatile polynuclear clusters with five to eight osmium atoms, for which their preparative details were established by experiments involving pyrolysis of $\mathrm{Os}_{3}(\mathrm{CO})_{12}$ in Carius tubes sealed under vacuum. ${ }^{19}$ As a result, the parent complex $\mathrm{Os}_{3}(\mathrm{CO})_{12}$ should be less suitable for CVD experiments, with respect to the more volatile, pyrazolate complexes 1 and 2.

\section{Deposition of thin films}

Deposition of Os metal thin film was first conducted using complex $\mathbf{1}$ in a home-made cold-wall CVD reactor, in the temperature range $450-550{ }^{\circ} \mathrm{C}$. Detailed conditions for the

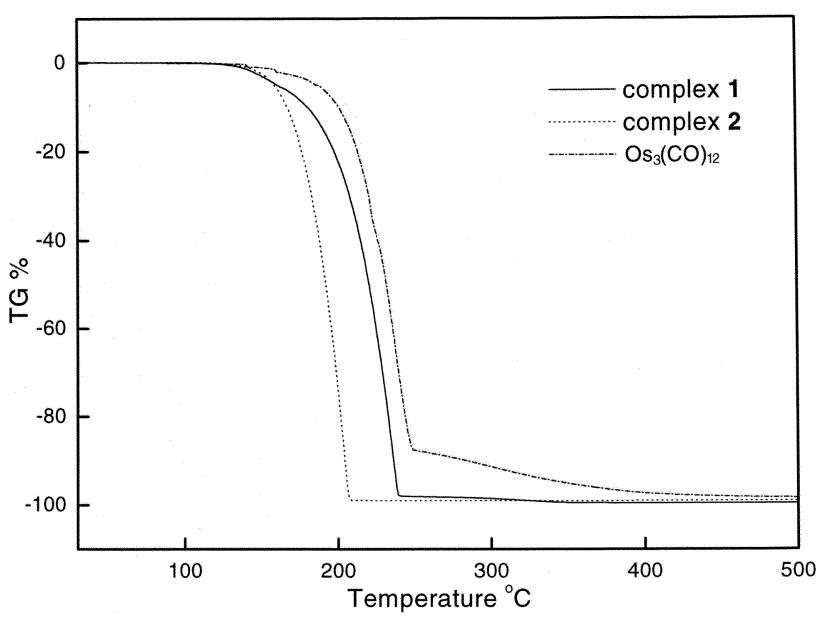

Fig. 4 Thermogravimetric analysis data for (a) complex 1, (b) complex 2 and $(c) \mathrm{Os}_{3}(\mathrm{CO})_{12}$. The TGA runs were carried out at atmospheric pressure with $\mathrm{N}_{2}$ as carrier $(100 \mathrm{sccm})$ and a heating rate of $10{ }^{\circ} \mathrm{C} \mathrm{min}^{-1}$.

deposition of the films are summarized in Table 4. The typical deposition time was adjusted to 10 and $15 \mathrm{~min}$. This source reagent was vaporized at $110{ }^{\circ} \mathrm{C}$, using a stream of $\mathrm{H}_{2}$ as carrier gas, of which the flow rate was adjusted to $20 \mathrm{sccm}$ under a pressure of 1 Torr.

Visually smooth film was observed on the substrate surfaces at $450{ }^{\circ} \mathrm{C}$. The as-deposited thin film exhibited a dark gray cast, and the scotch-tape peel test established a fairly good adhesion to the substrates. The SEM image is depicted in Fig. 5a. It shows that the surface consists of a loosely packed aggregation of metal clusters, which are in turn produced by fusion of smaller particles with dimensions $15-40 \mathrm{~nm}$. In addition to the presence of $4 \mathrm{at} \%$ of oxygen as determined by scanning the $\mathrm{O} 1 \mathrm{~s}$ peak at $531.0 \mathrm{eV}$, the XPS analysis indicated the presence of approximately $42 \mathrm{at} \%$ of carbon, which was gauged according to the relative intensity of $\mathrm{C} 1 \mathrm{~s}$ at $284.5 \mathrm{eV}$ with respect to those of the signals Os $4 d_{5 / 2}$ at $278.2 \mathrm{eV}$ and $4 d_{3 / 2}$ at $292.6 \mathrm{eV}$, while the nitrogen and fluorine contents fall below the detection limit of the instrument. Moreover, the XRD analysis showed three broad diffraction signals that can be identified as the (100), (002) and (101) planes of the hexagonally close-packed Os standard (Fig. 6a). It appears to us that the aggregation of metal cluster particles and the presence of excess of carbon contamination are two major factors that contribute to the broadening of all observed XRD signals.

The metal film becomes thinner (3400 $\AA$ ) for the deposition experiment carried out at $500{ }^{\circ} \mathrm{C}$. This is caused by partial deposition of metal on the wall of the inner vapor passage, which is located above the substrate heater. The depletion of source vapor then reduced the total amount of metal that can be deposited on the substrate surfaces. In addition to the reduction of the thickness, the as-deposited thin film exhibits many interesting variations of the basic properties. First, the color turns to bluish gray, which is akin to that of the bulk Os metal standard. As indicated by SEM analysis, the surface

Table 4 Deposition Ru thin films from the source reagents $\mathbf{1}$ and $\mathbf{2}$

\begin{tabular}{|c|c|c|c|c|c|c|c|}
\hline Film no. & Source & Carrier gas & Deposition $T /{ }^{\circ} \mathrm{C}$ & System $P /$ Torr & Thickness/Å & Impurities (at $\%$ ) & $\rho / \mu \Omega \mathrm{cm}$ \\
\hline 1 & 1 & $\mathrm{H}_{2}(20 \mathrm{sccm})$ & 450 & 1.0 & 9000 & $\mathrm{C}, 42 \% ; \mathrm{O}, 4 \%$ & 839 \\
\hline 2 & 1 & $\mathrm{H}_{2}(20 \mathrm{sccm})$ & 500 & 1.0 & 3400 & $\mathrm{C}, 9 \% ; \mathrm{O}, 4 \%$ & 82 \\
\hline 3 & 1 & $\mathrm{H}_{2}(20 \mathrm{sccm})$ & 550 & 1.0 & 2200 & $\mathrm{C}, 4 \% ; \mathrm{O}, 3 \%$ & 38 \\
\hline 4 & 2 & $\mathrm{H}_{2}(10 \mathrm{sccm})$ & 400 & 1.5 & 5280 & $\mathrm{C}, 48 \% ; \mathrm{O}, \sim 0 \%$ & 415 \\
\hline 5 & 2 & $\mathrm{H}_{2}(10 \mathrm{sccm})$ & 450 & 1.5 & 1580 & $\mathrm{C}, \sim 0 \% ; \mathrm{O}, 1 \%$ & 15 \\
\hline 6 & 2 & $\mathrm{H}_{2}(10 \mathrm{sccm})$ & 500 & 1.5 & 2520 & $\mathrm{C}, \sim 0 \% ; \mathrm{O}, 1 \%$ & 18 \\
\hline 7 & 2 & $\mathrm{H}_{2}(10 \mathrm{sccm})$ & 550 & 1.5 & 1820 & $\mathrm{C}, \sim 0 \% ; \mathrm{O}, 2 \%$ & 60 \\
\hline 8 & 2 & $\operatorname{Ar}(10 \mathrm{sccm})$ & 450 & 1.5 & 1750 & $\mathrm{C}, \sim 0 \% ; \mathrm{O}, 2 \%$ & 25 \\
\hline
\end{tabular}



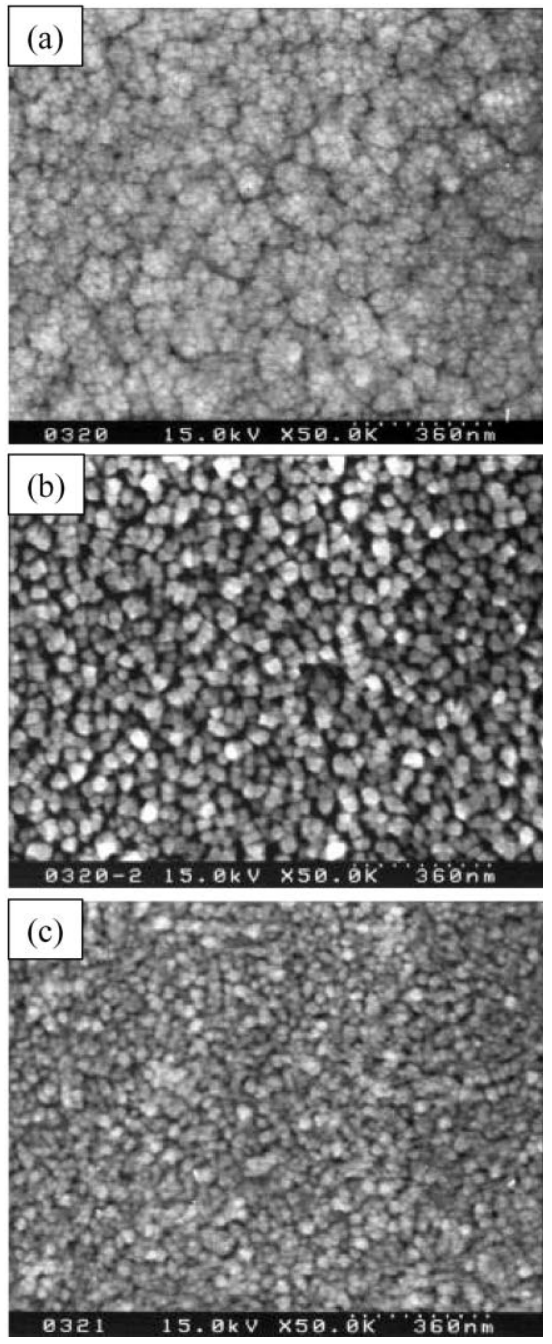

Fig. 5 SEM micrographs of the Os films deposited on Si wafers: (a) film 1, (b) film 2, and (c) film 3 .

morphology changed to a new pattern involving hemispherical grains with a very narrow distribution of particle sizes $20-40 \mathrm{~nm}$ (Fig. 5b). Although no formation of larger aggregated metal particles was observed, most of the particles at the surface were packed rather loosely, giving a rather rough substrate surface and showing many voids and large cavities between grains. This surface feature is somewhat consistent with the XRD data, which gives two sharp signals derived from (100) and (101) planes and a third less intense signal derived from the (002) planes (Fig. 6b). Moreover, the XPS analysis shows a

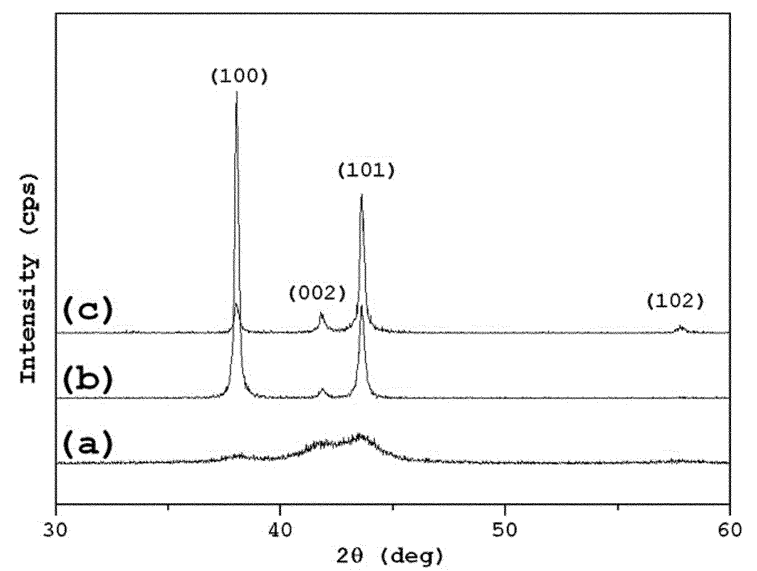

Fig. 6 X-Ray diffraction pattern of the as-deposited thin films: (a) film 1, (b) film 2 and (c) film 3. reduction of carbon content from 42 at $\%$ to 9 at $\%$, and a four-point probe measurement gives a reduction of electric resistivity from 839 to $82 \mu \Omega \mathrm{cm}$ for the films obtained at 450 and $500{ }^{\circ} \mathrm{C}$, respectively.

Upon further increasing to $550{ }^{\circ} \mathrm{C}$, the film deposited on the substrates has become even thinner $(2200 \AA)$. The color of the thin film remains bluish gray and SEM analysis shows the formation of a more densely packed surface morphology (Fig. 5c). The XRD analysis indicates a change of preferred orientation along the (101) planes (Fig. 6c), although this is not easily understood and requires more studies in the future. Examination by XPS analysis gives a reduction of carbon content to 4 at $\%$, together with 3 at $\%$ of oxygen. The electric resistivity measured by a four-point probe method gives a much better value of $38 \mu \Omega \mathrm{cm}$, showing optimal characteristics for the osmium thin film deposited from source complex $\mathbf{1}$ as the precursors. For comparison, bulk osmium has a resistivity of $8.1 \mu \Omega \mathrm{cm}$ at $0{ }^{\circ} \mathrm{C}$, so the resistivity is $\sim 5$ times greater than that for pure osmium, a result which is attributed to the $\mathrm{C}$ and $\mathrm{O}$ contaminations and in part to the poor contact between grains.

For Os thin films deposited from the second pyrazolate complex 2 , the source reagent was vaporized at a constant temperature of $115^{\circ} \mathrm{C}$, while the system pressure was tuned to 1.5 Torr and the carrier gas flow rate was kept at $10 \mathrm{sccm}$. The XPS analysis showed an elemental composition possessing only trace amounts of carbon and $\sim 1 \%$ of oxygen starting at $450{ }^{\circ} \mathrm{C}$. This purity is found to be much superior to that obtained at the lower temperature of $400{ }^{\circ} \mathrm{C}$, for which excess carbon content was observed throughout the thin film (48 at $\%)$. This result suggests that $450{ }^{\circ} \mathrm{C}$ is the optimal temperature for the effective removal of all non-metal impurities. Interestingly, in contrast to the previously obtained morphological patterns, the SEM picture showed densely packed crystalline particles with an approximate grain size of $30-70 \mathrm{~nm}$ by visual inspection (Fig. 7a). Examination of this thin film using XRD analysis showed the occurrence of strong (002) and (101) diffraction signals of Os metal standard (Fig. 8). The electrical resistivity was observed to be reduced to $15 \mu \Omega \mathrm{cm}$, which represents the best set of analytical data obtained in this system.

As the deposition temperature is further raised to $500{ }^{\circ} \mathrm{C}$, we observed that the carbon and oxygen contamination has remained at the same level of $\leqslant 1$ at $\%$, but the as-deposited thin film showed at least $200 \%$ increase in grain size (Fig. $7 b$ ). This observation can be understood in terms of the faster grain growth vs. nucleation on the substrate surface by increasing temperature. However, the as-deposited thin film started to exhibit serious agglomeration at $550{ }^{\circ} \mathrm{C}$ (Fig. 7c). The average size of the agglomerates is about $220 \mathrm{~nm}$, which is significantly larger than that observed in the thin film deposited at 450 $500{ }^{\circ} \mathrm{C}$. In the mean time, the XRD analysis shows a severe broadening of all diffraction signals (Fig. 8c), confirming the formation of a more amorphous structure and smaller grain sizes. It is possible that, due to the excessive thermal energy provided by the substrate heater, the CVD source reagent has undergone spontaneous decomposition in the gas phase to form small metal particulates. After forming physical contact with the substrate surface, these metal particulates immediately begin to serve as more effective nucleation sites in promoting the subsequent agglomeration and affording such abrupt changes in morphology.

Furthermore, a control CVD experiment was conducted under argon at $450{ }^{\circ} \mathrm{C}$ to study the possible influence of the carrier gas $\mathrm{H}_{2}$ that was used in previous deposition experiments. To our surprise, the elemental composition of this thin film gave only a slightly higher percentage for oxygen (2 at $\%)$, estimated using the XPS analysis, while the content of other impurities such as carbon all remained at the same level vs. the films obtained under $\mathrm{H}_{2}$. This implies that the reductive carrier gas is probably unnecessary to the effective removal of organics 

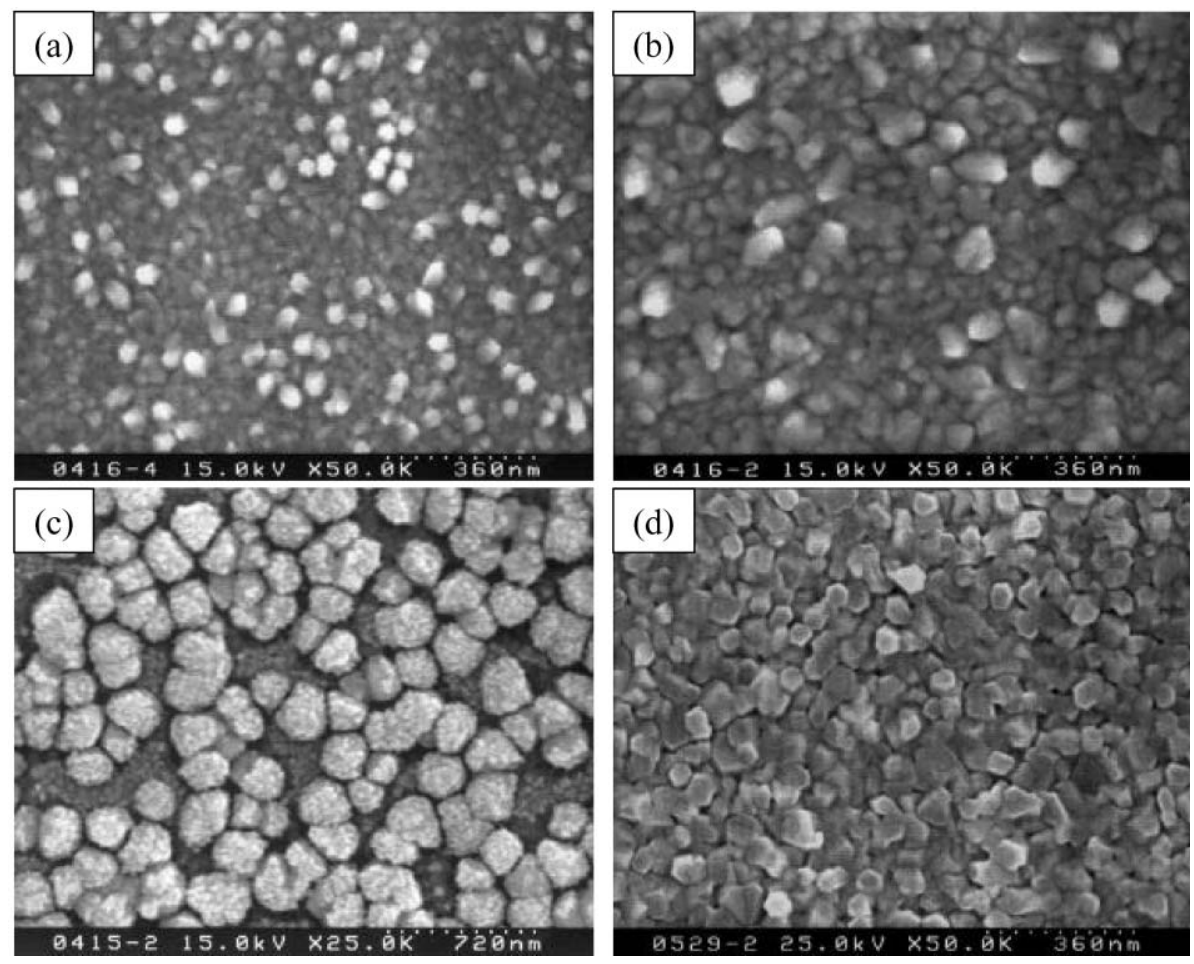

Fig. 7 SEM micrographs of the Os films deposited on Si wafers: (a) film 5, (b) film 6, (c) film 7 and (d) film 8 .

under this optimal condition. That is, the deposition may proceed via a parallel spontaneous CO desorption or other unknown process, which works as well as the proposed $\mathrm{CO}$ hydrogenation occurring under $\mathrm{H}_{2}$ atmosphere. The SEM micrograph depicted in Fig. $7 d$ demonstrates the additional effect of Ar carrier gas on the crystallinity of the metal thin film, for which the shape of the microcrystalline grams looks completely different from that obtained under $\mathrm{H}_{2}$ atmosphere. This observation is further verified by XRD, which shows a concurrent change of the preferred growth orientation from (101) planes to (002) planes, although the width of all diffraction signals seems to be much larger.

\section{Summary}

Two pyrazolate complexes $\mathbf{1}$ and $\mathbf{2}$ have been prepared, showing superior CVD characteristics compared to that of the parent complex $\mathrm{Os}_{3}(\mathrm{CO})_{12}$, mainly due to their higher volatility and greater proportion of sample that can be transported into the gas phase by sublimation. For complex $\mathbf{1}$, the deposition experiments were conducted in the temperature range 500 $550{ }^{\circ} \mathrm{C}$ under $\mathrm{H}_{2}$ atmosphere. The as-deposited thin film

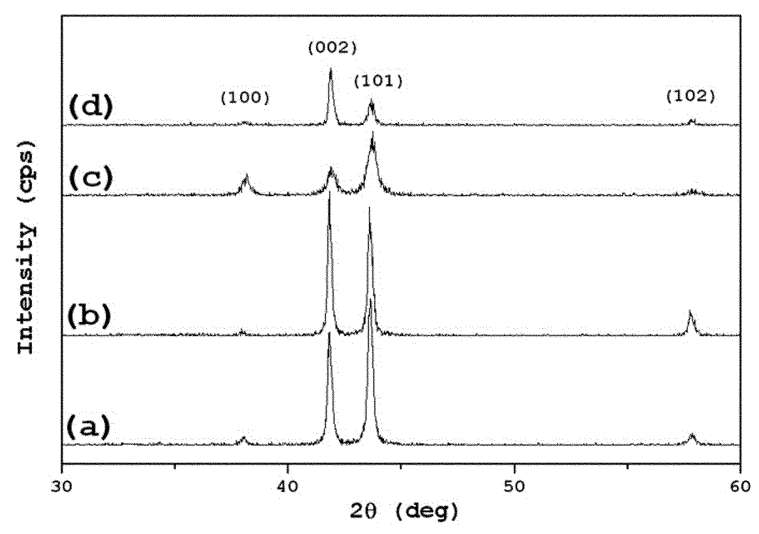

Fig. 8 X-Ray diffraction pattern of the as-deposited thin films: (a) film 5, (b) film 6, (c) film 7 and (d) film 8 . showed small amounts of carbon and oxygen; while fluorine and nitrogen were not observed within the detection limit of the instrument. A systematic reduction in the carbon content was observed upon increasing the temperature and it may be related to the $\mathrm{CO}$ hydrogenation reaction occurring on the substrate surface.

On the other hand, the deposition of Os metal from source complex 2 was best conducted at a lower temperature 450 $500{ }^{\circ} \mathrm{C}$. In contrast to the previous experiments using complex 1, the resultant metal thin film exhibited a continuous and densely packed microstructure and the content of carbon contamination dropped to a minimum value, showing the formation of superior metal thin films. Upon further increasing the deposition temperature to $550{ }^{\circ} \mathrm{C}$, the morphology of the thin films degraded substantially and large agglomerates were observed on the surface due to a spontaneous decomposition during gas phase transport. Switching the carrier gas from $\mathrm{H}_{2}$ to $\mathrm{Ar}$ at $450{ }^{\circ} \mathrm{C}$ also gave rise to the metal thin film with comparable content of carbon and oxygen. This finding shows that the $\mathrm{H}_{2}$ environment is not essential for the removal of carbon or oxygen on the osmium thin films derived from complex 2.

\section{Acknowledgement}

We thank the National Sciences Council of Taiwan (NSC 902113-M007-051) for support of the work.

\section{References}

1 The Chemistry of Metal CVD, ed. T. T. Kodas and M. J. HampdenSmith, VCH, New York, 1994.

2 (a) P. Doppelt, Coord. Chem. Rev., 1998, 178-180, 1785; (b) J.-C. Hierso, R. Feurer and P. Kalck, Coord. Chem. Rev., 1998, 178-180, 1811; (c) D. V. Baxter, K. G. Caulton, M. H. Chisholm, S.-H. Chuang and C. D. Minear, Chem. Commun., 1998, 1447; (d) C. Y. Lee, Chem. Vap. Deposition, 1999, 5, 69; (e) P.-F. Hsu, Y. Chi, T.-W. Lin, C.-S. Liu, A. J. Carty and S.-M. Peng, Chem. Vap. Deposition, 2001, 7, 28; (f) F.-J. Lee, Y. Chi, P.-F. Hsu, T.-Y. Chou, C.-S. Liu, S.-M. Peng and G.-H. Lee, Chem. Vap. Deposition, 2001, 7, 99.

3 (a) H. Inoue and K. Satoh, Bull. Chem. Soc. Jpn., 1999, 72, 
121; (b) Y. Hayakawa, K. Fukuzaki, S. Kohiki, Y. Shibata, T. Matsuo, K. Wagatsuma and M. Oku, Thin Solid Films, 1999, 347, 56; (c) R. Rella, P. Siciliano, L. Vasanelli, C. Gerardi and A. Licciulli, J. Appl. Phys., 1998, 83, 2369; (d) S. O. Ishii, F. Yoshimura, A. Terada and I. Sato, J. Appl. Phys., 1987, 61, 3825 .

4 S. Lehwald and H. Wagner, Thin Solid Films, 1974, 21, S23.

5 C. J. Smart, A. Gulhati and S. K. Reynolds, Mater. Res. Soc. Symp. Proc., 1995, 363, 207.

6 A. Tanaka, J. Electron Microsc., 1994, 43, 177.

7 A. D. Berry, D. J. Brown, R. Kaplan and E. J. Cukauskas, J. Vac. Sci. Technol., 1986, 4, 215.

8 E. P. Boyd, D. R. Ketchum, H. Deng and S. G. Shore, Chem. Mater., 1997, 9, 1154

9 (a) Y. Senzaki, F. B. McCormick and W. L. Gladfelter, Chem. Mater., 1992, 4, 747; (b) Y. Senzaki, W. L. Gladfelter and F. B. McCormick, Chem. Mater., 1993, 5, 1715.

10 Y. Senzaki, D. Colombo, W. L. Gladfelter and F. B. McCormick, Proc. Electrochem. Soc., 1997, 97-25, 933.

11 H.-L. Yu, Y. Chi, C.-S. Liu, S.-M. Peng and G.-H. Lee, Chem. Vap. Deposition, 2001, 7, 245.

12 O. Renn, L. M. Vananzi, A. Marteletti and V. Gramlich, Helv. Chim. Acta, 1995, 78, 993.

13 (a) G. M. Sheldrick, SHELXTL version 5.10, Siemens Analytical
X-ray Instruments Inc., Madison, WI, 1998; (b) Siemens, SMART and SAINT. Siemens Analytical X-ray Instruments Inc., Madison, WI, 1995; (c) G. M. Sheldrick, SADABS. University of Götingen, Germany, 1996.

14 J. R. Shapley, D. E. Samkoff, C. Bueno and M. R. Churchill, Inorg. Chem., 1982, 21, 634.

15 M. I. Bruce, M. G. Humphrey, M. R. Snow, E. R. T. Tiekink and R. C. Wallis, J. Organomet. Chem., 1986, 314, 311.

16 M.-D. Su, H.-Y. Liao, S.-Y. Chu, Y. Chi, C.-S. Liu, F.-J. Lee, S.-M. Peng and G.-H. Lee, Organometallics, 2000, 19, 5400.

17 (a) J. A. Cabeza, C. Landazuri, L. A. Oro, A. Tiripicchio and M. Tiripicchio-Camellini, J. Organomet. Chem., 1987, 322, C16; (b) J. A. Cabeza, C. Landazuri, L. A. Oro, D. Belletti, A. Tiripicchio and M. Tiripicchio Camellini, J. Chem. Soc., Dalton Trans., 1989, 1093.

18 (a) J. A. Samuels, E. B. Lobkovsky, W. E. Streib, K. Folting, J. C. Hoffman, J. W. Zwanziger and K. G. Caulton, J. Am. Chem. Soc., 1993, 115, 5093; (b) J. A. Samuels, K. Folting, J. C. Huffman and K. G. Caulton, Chem. Mater., 1995, 7, 929; (c) Y. Chi, S. Ranjan, P.-W. Chung, C.-S. Liu, S.-M. Peng and G.-H. Lee, J. Chem. Soc., Dalton Trans., 2000, 343.

19 C. R. Eady, B. F. G. Johnson and J. Lewis, J. Chem. Soc., Dalton Trans., 1975, 2606. 